\title{
ELEMENTOS EM TRANSIÇÃO EM OS MENINOS CRESCEM E A ÚLTIMA TROPA, DE DOMINGOS PELLEGRINI
}

\author{
Andrius Felipe Roque ${ }^{1}$ \\ Luciana Pereira Jasinski²
}

\begin{abstract}
RESUMO: retratando o cenário do norte pioneiro, Domingo Pellegrini criou obras representativas da literatura paranaense, como $O$ homem vermelho (1977) e O caso da chácara chão (2000), que garantiram ao autor dois Prêmios Jabuti. Apesar do regionalismo, seus textos dialogam com o humano em busca do existencial, daquilo que permanece apesar das transformações no ambiente. Para ele, o homem luta para continuar a ser o mesmo, ainda que mais moderno. Percorrem suas histórias conflitos de transitoriedade, em dimensões sociais, familiares e pessoais. A este trabalho, portanto, cabe analisar elementos em transição presentes em duas obras do escritor londrinense, Os meninos crescem (1977) e $A$ última tropa (1998). O primeiro livro reúne alguns contos reescritos de Os meninos (1977), e outros inéditos, situando a infância e a adolescência como temas. O segundo narra a história de um garoto de Tibagi, que parte para a última viagem tropeira do grupo do pai, com o objetivo de vender mulas em São Paulo. Em análise desses textos, é estabelecido diálogo entre a ficção realista de Pellegrini e as transformações sociais que o Brasil vivenciava partir da metade do séc. XX, como o acesso aos automóveis, a legalização do divórcio e o intenso êxodo rural. Paralelamente, também há os conflitos da adolescência nas personagens meninos, caracterizando um período de transição pessoal (moral, psicológica e sexual). Esse jogo entre modernização e afirmação pessoal, então, movimenta as personagens na trama, de modo a revelarem a crítica do autor à perda de valores tradicionais, que sucumbem à modernidade.
\end{abstract}

PALAVRAS-CHAVE: Literatura Paranaense. Modernização. Adolescência.

\section{ELEMENTS OF TRANSITION IN OS MENINOS CRESCEM AND A ÚLTIMA TROPA, BY DOMINGOS PELLEGRINI}

\begin{abstract}
Domingos Pellegrini created representative works of the Paranaense literature, as O homem vermelho (1977) and O caso da chácara chão (2000), that ensured two Jabuti Prices to the author. Despite of the regionalism, his texts dialogue with the human in search of the existential, what resists to environmental changes. To him, man fights to continue to be the same, even more modern. Conflicts of transience, in social, familiar and personal dimensions, are very present in his stories. Therefore, this work aims to analyze elements in transition that are in two Pellegrini's books, Os meninos crescem (1977) and A última tropa (1998). The first one has some rewritten short stories from Os meninos (1977), and another unpublished ones, presenting childhood and adolescence as themes. The second one tells the story of a boy from Tibagi who goes to the last droving trip of his father's group, aiming to sell mules in São Paulo. In the analysis of these texts, a dialogue is established between the realist Pellegrini's fiction and the social changes that Brazil was living since the half of $20^{\text {th }}$ Century, as the access to automobiles, the legalization of divorce and the intense rural flight. At the same time, there are the adolescence conflicts in the boy characters, drawing a period of personal transition (moral, psychological and sexual). This game between modernization and personal affirmation, so, moves the characters of the plot, revealing author's criticism to the lost of traditional values, that succumb to modernity.
\end{abstract}

KEY-WORDS: Paranaense Literature. Modernization. Adolescence.

- Enviado em 13/05/2017

- Aprovado em 28/06/2017

${ }^{1}$ Licenciado em LETRAS PORTUGUÊS-INGLÊS pela Universidade Tecnológica Federal do Paraná (UTFPR) e pósgraduando no curso de Especialização em Educação Profissional Técnica de Nível Médio. Email: andriusfr@outlook.com

${ }^{2}$ Mestre em Linguística pela Universidade Federal do Paraná. Email: lucianajasinski@gmail.com 


\section{INTRODUÇÃO}

Domingos Pellegrini nasceu em 1949, em Londrina, cidade onde ainda mora, na sua Chácara Chão. Estudou Letras e, além de publicar livros, trabalha como jornalista e atua na área da propaganda, tendo também já se inscrito na política, como Secretário da Cultura no segundo mandato de Antônio Belinati. Suas obras se reúnem em dezenas, desde contos, romances e literatura infantil. Duas delas Ihe valeram Prêmios Jabuti, primeiro com $O$ homem vermelho (1977), depois com O caso da chácara chão (2000).

Representante de peso da literatura paranaense, Pellegrini retrata, quase sempre, o cenário do norte pioneiro. Apesar do regionalismo, seus textos dialogam com o humano em busca do existencial, daquilo que permanece apesar das transformações no ambiente. Para ele, o homem continua a ser o mesmo, ainda que moderno. Seu estilo de linguagem é peculiarmente simples, o que veicula sua crença de que o escritor deve ter sua própria versão da língua. (SAMWAYS, 1988).

Neste trabalho, pois, buscamos analisar a transitoriedade que percorre duas de suas obras, Os meninos crescem (1977) e A última tropa (1998). Ambas interagem com a história de um Brasil que se direciona a rumos modernos, que é o país de 1930 à década de 1980. Essa modernização, então, movimenta as personagens, que, em alguns casos sucumbem, porém em outros se mantém. Aqui, portanto, temos a crítica do autor à perda dos valores tradicionais.

\section{OS MENINOS CRESCEM}

Escrito na década de 1970 e publicado em 1977, Os meninos crescem reúne as melhores histórias de Os meninos (1977), totalmente reescritas, além de algumas inéditas. Sua visão de repórter social e de contista parece indicar uma (pseudo) autobiografia, uma nostalgia às lembranças da infância. Mas o que se evidencia é um país em profunda mutação sócio-histórica, que é o Brasil (mais especificamente o norte pioneiro paranaense e São Paulo) do séc. XX, cenário dos contos ali narrados. 
Nesse pano de fundo, as personagens parecem estar conectadas por um longo fio condutor, representado pela predominante transição:

Assim, as personagens estão sempre entre: entre o campo e a cidade, entre a cidade e o mar, a infância e a adolescência, a mocidade e a velhice; os filhos divididos entre pais e mães, a família divida entre gerações; os cidadãos entre a revolta ou humilhação, entre a nostalgia e a ação (PELLEGRINI,1987).

Em comum, também, é a presença de um menino, que ora configura o foco narrativo, ora está ali, somente como personagem que se depara com as mais diversas experiências. Consequência disso é a recorrência de 1aa pessoa, apesar de que alguns contos escapam para a 3a.

Dessa forma, propomo-nos a analisar o movimento de transição que percorre a narrativa. Sob ele, vemos a sujeição de dois elementos: 1) a família e 2) os meninos. No primeiro caso, há um contexto sócio-histórico em jogo, que além de se constituir como espaço das ações na obra, determina a problemática que desenvolve a história. Já no segundo, temos a transformação pessoal que marca a trajetória das personagens, em especial, dos meninos.

\subsection{A família entre}

Todos os contos de Os meninos crescem têm a família retratada, exceto $O$ aprendiz. Essa retratação é, quase sempre, sobre uma mitológica família brasileira, em que temos o Pai, a Mãe, o Tio, o Vô, a Vó, a Irmã. Essas personagens, às vezes, atuam como tipos, até mesmo pela ausência de nome que os individualizem.

Essa clássica estrutura familiar, no entanto, está passando por alterações, que se dão no nível espacial, moral e mesmo no composicional. É em volta dessa transição que Pellegrini circunscreve a família, que pode ser representada como reacionária, ou cedendo a novos paradigmas.

Em Minha estação de mar, conto que abre o livro, lemos a história de uma família que sofre a inserção de um novo objeto em seu meio: um carro. Assim, eles promovem uma conturbada viagem à praia, para que o garoto conheça o mar. Ali temos Pai, Mãe, Irmã (Alice), 
menino (narrador-personagem) e mais uma agregada (Linalva). Essa família vive a transição ao moderno, a partir do momento em que compram o automóvel. Tal mudança, por sua vez, se reflete no plano do espaço, que é a ida à praia. No entanto, tanto o veículo quanto o mar não são tomados como elementos eufóricos (de valores semânticos que se relacionam a sentimentos positivos, de alegria e bem estar). Para o primeiro, temos: "Naquele tempo a escola era a única prisão que eu conhecia, até o dia em que Pai comprou um carro" (PELLEGRINI, 1987; p.08). Já quanto ao segundo, vemos que, no fim do texto, a estação de mar foi a única que não deixou marcas nas mãos, ou seja, não foi tão relevante quanto se imaginava, asserção que se baseia na decepção que o garoto teve.

Outra família que se encontra entre a tradição e o moderno é vista em $O$ último porco. É a história de dois garotos que passam os Natais em grandes festas, que juntam toda a gente. Mas, com a morte do Vô, isso vai se perdendo, até que os pães, o porco e toda a culinária da Vó são substituídos pela compra de metade de um porco, um panetone e um peru já temperado, que apita quando bem assado. Aqui há a decadência dos valores morais da família, que resulta na sua dispersão. O narrador nos apresenta isso com um sentimento de perda em face à modernização.

Sob a perspectiva de Domingos Pellegrini, esses textos procuram retratar um Brasil em transformações sócio-históricas. O país que saia de Vargas e caminhava em direção à ditadura buscava mostrar o aparente progresso. Dos anos 1950 em diante, cria-se que logo a modernização se estabeleceria em nossas fronteiras, e assim passaríamos ao Primeiro Mundo. A economia, os padrões de consumo e de produção se alinhavam ao dos países desenvolvidos. Assim, tínhamos petróleo, energia das grandes hidrelétricas, produção de metais, automóveis e eletrodomésticos. Além disso, nas grandes cidades, o alimento industrializado predominava. Surgem os supermercados. Os shopping centers.

E a tradição e os valores interioranos, então, tornam-se estigmas e perdem-se diante desses avanços:

Matutos, caipiras, jecas: certamente era com esses olhos que, em 1950, os 10 milhões de citadinos viam os outros 41 milhões de brasileiros que moravam no campo, nos vilarejos e cidadezinhas de menos de 20 mil habitantes. Olhos, portanto, de gente moderna, "superior", que enxerga gente atrasada, "inferior". A vida da cidade atrai e fixa porque oferece melhores oportunidades e acena um futuro de progresso individual, mas, 
também, porque é considerada uma forma superior de existência. A vida do campo, ao contrário, repele e expulsa (MELLO, 1998; p. 574).

Dessa forma, outro aspecto de transição se dá, agora, no nível espacial: é a migração entre rural e urbano. As personagens de $O$ melhor natal se encontram nisso. Enquanto o garoto descobre novos mundos, a Mãe tenta convencer o Pai a se mudar para a cidade, frente ao declínio que enfrentam e influenciada pela visão dos parentes que vêm da cidade para a festa de Natal. Tomadas as decisões, tudo parece mudar, como é anunciado: "Um galo cantou: Vai nascer um novo tempo! - o tio imitou um cocoricó - Mas um passarinho corrigiu: Um novo dia, um novo dia!" (PELLEGRINI, 1987; p.205).

O séc. XX é assaz marcado pelo êxodo rural e o inchamento das grandes cidades:

\begin{abstract}
A maior e mais importante de todas as alterações é a inversão da relação campo/cidade, onde a população rural, em 1950 , representava $64 \%$ da população total e a população urbana $36 \%$, passando, em 1980 , a primeira para $33 \%$ e a segunda para $67 \%$ da população total. O eixo econômico desloca-se, assim, do campo - cenário tradicional e secular da produção de riquezas - para as cidades, com a explosão de megalópoles [...] (SILVA, 1990).
\end{abstract}

Em alguns momentos, a família parece estar entre a felicidade e a crise. Em Visita ao zoológico, há o sofrimento pela perda do emprego do Pai. O dia que a Mãe tinha destinado para cobrar as responsabilidades paternas em casa tornou-se o tão esperado passeio. Mas ao voltarem, Pai e Filho foram recebidos por uma mãe cuidadosa, que agora sabia o que havia acontecido. Por fim, eles acabam felizes, superando a dificuldade. Essa crise, porém, parece indicar novos rumos na configuração familiar, pois a mãe se propõe a sair para trabalhar, deixando a casa aos cuidados da Vó.

Nesse caso, a família não cede à crise. Todavia, em Gente-grande, o tema é justamente a desagregação familiar. Essa história tensa nos é mostrada pela visão do garoto já adulto, em tom memorialista. $O$ texto se inicia assim:

Era domingo quando Pai e Mãe se separaram, armava tempestade e eu era menino mas lembro como se fosse hoje. Minha irmã nunca brincava comigo, mas naquele dia fomos brincar num canto da cozinha enquanto eles gritavam batendo portas e gavetas pela casa; 
ela pisando as roupas dele, jogando pelas janelas, e ele catando enquanto procurava documentos e sapatos (PELLEGRINI, 1987; p.155).

A instituição do divórcio no Brasil é fruto da mesma época em que Os meninos Crescem foi publicado. Na verdade, eles até coincidem em ano, 1977, com a promulgação da Lei $\mathrm{n}$ o 6.515/1977, de dezembro, em que passou a ser permitido aos divorciados a realização de novo matrimônio. Antes disso, tínhamos no Código Civil o Artigo 315, que somente estabelecia a separação sem dissolução de vínculo, isto é, o chamado desquite (BERQUÓ, 1998).

Ao comparar os censos de 1940 a 1991 (IBGE), vemos um crescimento de 4,1 \% no número de pessoas divorciadas ou separadas. Nesse sentido, Pellegrini parece estar indicando novas tendências no arranjo da família brasileira. Essa situação caótica, por sua vez, é criticada na ironia do próprio título do conto. Todos os problemas criados e os seus efeitos nas crianças são tomados friamente, e, no fim, "gente-grande sabe o que faz". A família que estava entre a felicidade e a crise, então, sucumbe. Mas triste mesmo é a realidade brasileira em que o texto se espelha.

\subsection{Meninos entre}

O próprio título da obra já indica a fase de mudanças pela qual as personagens menino estão passando. Pellegrini havia escolhido a seguinte epígrafe para o livro, que foi descartada: "Em todos os homens há um menino. Em todos os meninos, um homem". Essa frase representa justamente o paradoxo que é a adolescência, em que os garotos vivem, concomitantemente, a infância e as descobertas de adulto.

Na 2a edição, da Editora Busca Vida, a imagem da capa retrata perfeitamente esse momento: de um lado, temos a metade de um garoto com traços físico de ainda criança, o estilingue no bolso, a bola de futebol e outro amigo infantilmente semelhante. Já à direita, temos a outra metade que está vestida como homem, revólver escondido na cintura, cigarro no dedo e, mais ao canto, a figura de uma mulher nua em um ambiente nebuloso.

Todas as histórias têm a figura do menino, que, frequentemente, coincide com o narrador. Assim, essa mutação parece se dar tanto no interior de um mesmo conto, como também 
entre contos, como se tivéssemos a mesma personagem em diferentes fases, que são três: 1) a infantil, 2) o período de transição, e 3) a conquista final do mundo de homem.

Na história que inicia a narrativa, Minha estação de mar, já analisada aqui tendo a família como objeto, temos um típico infante. Ele está ainda muito ligado às brincadeiras (pião, bolinha de gude, bafo, colher manga, carrinhos de rolimã). E as suas ações são sempre descritas como trapalhadas de criança, que mexe em tudo que vê, que não tem paciência por muito tempo, inquieto. Isso tudo recheia o conto de muito humor:

[...] e fiquei sem ter o que fazer. Passavam os canaviais mais compridos e os maiores cafezais do mundo, e comecei a empurrar os bancos com os pés, mas não podia. Comecei a mexer nas maçanetas mas podia muito menos. Então encostei a cara no vidro da janela mas nem isso podia. Examinei o cinzeiro por dentro e por fora várias vezes [...]. Aí descobri a lâmpada do teto, e apaguei e acendi até Pai mandar parar. Consegui tirar o cinzeiro e ele mandou botar de volta no lugar. [...] E assim fui aprendendo tudo que não se pode fazer num carro (PELLEGRINI, 1987; p.12-13).

Outro conto que tematiza muito bem o universo infantil é $O$ herói. Ao fim da tarde, o garoto resolveu que deveria salvar o dia. E nesse intuito ele sai de casa, e começa uma narrativa que mescla realidade e imaginação, o que expressa a forma como as crianças parecem depreender o mundo. Porém, essa mistura é rompida, por um instante, no momento em que o menino presencia o atropelamento de um cachorro. A imagem do animal morto acaba perseguindo-o, até que se supera esse choque com a morte, e o controle da imaginação volta ao garoto, que conta aos amigos sua versão dos fatos, em que ele, obviamente, é o herói.

Em outras histórias, a figura do menino aparece descobrindo novos horizontes. Esse período de maturação, digamos assim, dá-se, principalmente, no contato com dois elementos: as drogas e o sexo. Esse se refere não somente a cópula propriamente dita, mas a sexualização em geral, que envolve o beijo, a interação com garotas e, especialmente, a masturbação. Aquelas englobam a bebida alcoólica e também o cigarro.

Em uma progressão, temos primeiro o protagonista de $O$ melhor natal. Ali vemos os primeiros estágios da puberdade. Sofrendo a influência de dois outros, ora o amigo, ora o primo, o garoto passa a reconhecer o feminino. Era a preta lavadeira, a mulher no recorte da revista, era a prima. E duas vezes ele presenciou os mais velhos se masturbando, como a seguir: 
- Nunca viu pinto de homem, guri? - o primo sorria torto, de repente era um desconhecido. A mão subia e descia - e o primo parecia ter esquecido dele, só olhava a revistinha, depois nem isso: fechou os olhos e tremeu apertando as coxas, ficou se lambuzando encostado na tora, rodeado de flores (PELLEGRINI, 1987; p.205).

E, dessa forma, a sexualidade do menino vai sendo desenvolvida na narrativa. A partir de certa parte, ele começa a se "relacionar" com a prima. A descrição dessa relação, que mistura brincadeiras e "contato sexual", acontece implicitamente. O próprio "esconde-esconde" já parece indicar essa conotação. O texto finaliza, então, com o garoto se masturbando.

Apesar dessa adolescida, no todo da obra, ela representa um primeiro estágio da transição. Já em $O$ aprendiz, os avanços são mais profundos. É a história de um garoto que, em meio à pressão social (dos amigos), descobre o os atributos femininos, como em um processo seriado, em que cada etapa se realiza em uma noite. Em termos narrativos, temos um detalhamento que reflete bem o estilo do autor:

Mas devagar ele começou a rebolar, subiu outra mão e agora pegava os dois peitinhos, juntava um com o outro e fazia um rego onde passava o dedão, e tornava a afastar as mãos, apertava os biquinhos, ela gemia e estremecia em contorções, erguia os ombros doidinha (PELLEGRINI, 1987; p.78).

O título do conto exprime justamente a idéia da sexualização, que é um dos aprendizados que transformará o garoto em homem. E ambos os contos aqui comentados mostram como a personagem se sente perante o desprendimento da sua condição de infante. E o sexo surge como força que impulsiona essa transição. Os especialistas no assunto reconhecem a função dessa prática:

Segundo OSÓRIO (1992), a adolescência é uma etapa da vida na qual a personalidade está em fase final de estruturação e a sexualidade se insere nesse processo, sobretudo como um elemento estruturador da identidade do adolescente (CANO, 2000). 
No caso de $O$ aprendiz, a identidade da personagem emerge sob as exigências sociais, isto é, a coerção dos amigos. Isso porque, nesse momento de formação, há uma necessidade de pertencer a uma comunidade, o que pode requerer certos moldes de caráter. Quanto ao adolescente, Almeida (2008) considera que,

\begin{abstract}
paralelamente, ao desenvolvimento físico interno e externo, ocorrem também, modificações de caráter social (FIERRO, 1983; CAMPOS, 1986; DOLTO, 1986; OSORIO, 1992; OUTEIRAL, 1994; BECKER, 1994; CARRETERO; CASCÓN, 1995; PALACIOS, 1995; GOLDENSTEIN, 1996; ZAGURY, 1996; ESSLINGER; KOVÁCS, 1999; ALMEIDA, 2003). O grupo de amigos tende a aumentar em importância e a tendência à imitação e identificação acentua-se marcadamente. Assim, a forma de se vestir, de falar, de agir, até mesmo os gostos tendem a ser muito influenciados pelo grupo. Temem não serem aceitos e valorizados pelos amigos e, portanto, procuram agir de acordo com o que faz a maioria, num processo de identificação com o grupo e seus componentes.
\end{abstract}

Nessa tentativa de agir como a massa, é que aparecem também as drogas. 0 álcool aparece nas duas histórias, claro que na primeira de uma forma mais tênue, com o vinho misturado com água na festa de natal, enquanto que na segunda já se tinha pinga com cinzano, além do uso cigarro, que na narrativa indica um nível mais "avançado" na escala de desenvolvimento. Essa diferença reforça o entendimento de que há uma progressão entre contos, como já comentado.

Por fim, chegamos à terceira fase em que se encontram algumas personagens de Os meninos crescem. Esse é a parte em que a conquista do mundo adulto se dá como definitiva. E o conto que melhor expressa tal idéia é $A$ noite em que achei meu pai. Lemos a história de um jovem que, ainda menor de idade, observava com seu amigo o movimento da zona e, às vezes, se relacionava com alguma prostituta que o abordava lá fora, já que ele não podia entrar. Até que, um dia, ele encontrou seu pai por lá, e passaram a noite em companhia, tomando algumas cervejas num bar próximo. Tempo depois, o pai levou o filho para dentro do prostíbulo. A última das barreiras da meninice, então, foi rompida. Nesse caso, é interessante ver que é a figura paterna que proporciona esse acesso ao mundo adulto, ao "ser homem". Toda essa situação, porém, muda a visão do jovem, o que é parte do processo, como afirma Cano (2000): “As mudanças físicas correlacionadas com as mudanças psicológicas levam o adolescente a uma nova 
relação com os pais e com o mundo".

\section{A ÚLTIMA TROPA}

Livro de 1998, esse conto longo ou romance curto narra a história de um garoto de Tibagi, que integra a tropa do pai numa longa e derradeira viagem para venda de mulas em São Paulo. Enquanto o troperismo parece entrar em decadência na sociedade brasileira, o menino amadurece conforme conquista a arte de tropear. Anos depois, quando já adulto, ele resgata seu passado, com a esperança de que sempre haverá uma nova tropa. Uma nova geração partindo.

Essa obra tem uma estreita relação com seu autor, que era neto de tropeiros. Ele nos conta que

estava em Castro, no Paraná, que foi importante pouso de tropeiros, e, justamente no Museu do Tropeiro, agachei para ler um texto ao lado de um fogão de trempe. Ali se contava que numa tropa todos e cada um eram importantes, como o cozinheiro, que garantia comida boa e bastante para todos. Ou o menino madrinheiro, montando a égua madrinha, que levava a tropa de mulas. Então, lendo aquilo, me emocionei e, quando levantei, já sabia que ia escrever a história de um menino tropeiro (PELLEGRINI, 1998; p.143).

Com esse intuito, então, Pellegrini cria sua ficção, que também é recheada de fatos da história do Brasil, principalmente como retrato da cultura tropeira. Propomos-nos, pois, a analisar como se dá essa relação sócio-histórica, apontando as transformações que ocorriam nesse período de transição que é a segunda metade do séc. XX.

\subsection{Um período em mutação}

O tropeirismo sustentou o trabalho nas fazendas do país durante quase dois séculos. As mulas eram buscadas no Rio Grande do Sul, e, durante todos esses anos, locais de parada foram se fixando, e, assim, muitas cidades se formaram ao longo das estradas por onde passavam as tropas. No Paraná, as principais são Lapa, Ponta Grossa e Castro, que estavam na rota do Caminho do 
Viamão, que ligava o RGS à Sorocaba. Nessa última, constitui-se uma grande feira para venda, em especial, de mulas, além de alguns utensílios próprios do tropeirismo. Ela se manteve até o final do século XIX. A partir daí, o comércio de muares passou para a cidade de Itapetininga, SP.

Na primeira metade do século XX, enquanto já rodavam carros e trens, em quase 20 mil km de malha ferroviária, algumas tropas ainda se aventuravam, e apareciam como alternativa válida à carência do sistema de transportes brasileiro:

uma visão geral da evolução histórica do sistema de transportes no Brasil, entre 1850 e 1950, mostra-nos sua precariedade. Diante da vastidão de seu território, quando se observa na de 40 deste século a pequena extensão de vias férreas e de estradas pavimentadas é que se pode verificar o quanto o país encontrava-se aquém de suas necessidades. Até o advento das ferrovias, as mercadorias eram tradicionalmente levadas aos portos em lombos de burros, cuja utilização decrescia na medida da entrada daquele novo meio de transporte na região produtora. Entretanto, a expansão da rede ferroviária, apesar de relativamente rápida, em termos absolutos cobria uma área de fato pequena (MONTEIRO,1990; p. 218-219).

Essa tradição, por sua vez, é o elemento mais forte em $A$ última tropa. Ela está representada, principalmente, na figura do Pai. Ele insiste em tropear, mesmo que tenha que dividir a estrada com os caminhões, mesmo que os indícios de uma decadência se apresentem, como vemos ao longo da narrativa. $E$, em todos os momentos em que se comenta o fim do tropeirismo e do uso das mulas, seu Zé de Tibagi fica nervoso. Um episódio que ilustra esse reacionarismo do tropeiro é quando aparece um jornalista querendo os entrevistar. Quando se afirma que aquela poderia ser a última tropa, Pai cospe e solta um palavrão. O periodista pede desculpas, mas comenta que, com as geadas, até quem tinha mulas nos cafezais estava vendendo.

Ao fim, quando as mulas enfim são vendidas e a família tem de se reorganizar economicamente, seo Zé teve que ceder aos novos ares da modernidade. O que acarretou na sua morte, mas não na morte da tradição: "O menino agacha para olhar as flores. O moço olha as fotos. - Do que morreu o vô, pai? - Acho que de saudade. - Saudade do que, pai? - Da vida de tropeiro" (PELLEGRINI, 1998; p.134).

O livro, então, trata de um momento de transição, da ascensão da modernidade, em detrimento do movimento tropeiro. Caracteriza-se pelo intenso êxodo rural e pela conseqüente 
tentativa de reorganização profissional. Na obra, Gaúcho, peão que compunha a tropa, vira motorista de táxi, enquanto Zico, o cozinheiro, tem um restaurante, ou seja, ambos continuam no mesmo ramo de trabalho, mas só se adaptam ao moderno.

Todavia, a voz do autor ecoa e mostra que, apesar das transformações sócio-históricas, o valor da tradição não se perde. É nesse sentido que o garoto volta, quando já adulto, à cidade natal, em busca de reviver o passado e passar aos filhos essa cultura tropeira. Dessa forma, pois, 0 texto se conclui, assegurando que sempre virá uma nova tropa: a nova geração. A última, ainda não.

\section{CONSIDERAÇÕES FINAIS}

Ao fim e ao cabo, pudemos ver que os livros nos retratam não só garotos crescendo, mas uma família em reconfiguração, que é a brasileira. As transformações sócio-históricas que o século XX presenciou compõem o background de Os meninos crescem, e o grupo familiar, ali, é também eixo central dessa transitoriedade que percorre toda a leitura. Paralelamente ao desenvolvimento social, há uma mutação psicológica na vida das personagens meninos, que pode ser vista intracontos ou intercontos. Já em A última tropa, enquanto o tropeirismo está em decadência e o pai sucumbindo, o garoto está em ascensão, tornando-se homem, e tropeiro.

Apesar dos embates que a modernidade traz, os valores se mantêm. É o amor entre família (mesmo nas brigas), a amizade, a felicidade nas pequenas coisas, a superação da morte, o posicionamento político. Essas qualidades são os universais do regionalismo de Pellegrini, captados pela lente do repórter, que se detém ao cotidiano. E é daí que surge a maior força de identificação entre leitor e obra.

\section{REFERÊNCIAS}

ALMEIDA, Thiago de. Adolescência em perspectiva: alguma visões e evolução sobre este conceito. Disponível em http://www.psicopedagogia.com.br/artigos/artigo.asp?entrlD=1033. 2008. 
BERQUÓ, Elza. Arranjos familiares no Brasil: uma visão demográfica. In SCHWARCZ, L. M. História da vida privada no Brasil: contrastes da intimidade contemporânea. 4a reimpressão. SP: Companhia das Letras, 1998.

CANO, M.A.T.; FERRIANI, M.das G.C. Sexualidade na adolescência: um estudo bibliográfico. Rev.latino-am.enfermagem. Ribeirão Preto, v. 8, n. 2, p. 18-24, abril 2000.

MELLO, João M. C. de; NOVAIS, Fernando A. Capitalismo tardio e sociabilidade moderna. In SCHWARCZ, L. M. História da vida privada no Brasil: contrastes da intimidade contemporânea. 4ạ reimpressão. SP: Companhia das Letras, 1998.

MONTEIRO, Hamilton de M. O aprofundamento do regionalismo e a crise do modelo liberal. In LINHARES, Maria Y. História geral do Brasil. Rio de Janeiro: Campus, 1990.

PELLEGRINI, Domingos. A última tropa. São Paulo: Moderna, 1998. . Os meninos crescem. 2ªed. São Paulo: Busca Vida, 1987.

SAMWAYS, Marilda Binder. Introdução à literatura paranaense. Paraná: Livros HDV, 1988.

SILVA, Francisco Carlos Teixeira. A modernização autoritária: do golpe militar à redemocratização. In LINHARES, Maria Y. História geral do Brasil. Rio de Janeiro: Campus, 1990. 